\title{
The new face of enterohaemorrhagic Escherichia coli
} infections

A Jansen (andreas.jansen@ecdc.europa.eu) ${ }^{1}$, J T Kielstein ${ }^{2}$

1. European Centre for Disease Prevention and Control (ECDC), Stockholm, Sweden

2. Department of Nephrology and Hypertension, Medical School Hannover, Germany

The unprecedented outbreak of Shiga toxin/verotoxin-producing Escherichia coli (STEC/VTEC) 0104: 44 in Germany in May and June 2011 displayed several novel epidemiological, microbiological and clinical features. Infection with STEC/VTEC, also referred to as enterohaemorrhagic E. coli (EHEC), with or without haemorrhagic uraemic syndrome (HUS), which is usually a disease of pre-school children and equally distributed among the sexes, affected in the current outbreak mostly women over the age of 20 years (87\%). In addition, several intriguing microbiological characteristics of the new epidemic strain have just been published $[1,2]$.

With regard to the clinical characteristics, STEC/VTEC 0104: $\mathrm{H}_{4}$ again differed remarkably from previously described STEC/VTEC infections. During a telephone conference on 9 June, organised by the European Centre for Disease Prevention and Control (ECDC) with clinical experts and nephrologists from 16 Member States of the European Union (EU) and several European and national professional societies, German colleagues shared their first clinical experiences from their patients. Severe infection with STEC/VTEC 0104: $\mathrm{H}_{4}$ usually presented as a disease in three phases. On admission, about $80 \%$ of the patients suffered from bloody diarrhoea and $20 \%$ from watery diarrhoea. In $25 \%$ of the cases with bloody diarrhoea, signs of HUS (based on laboratory parameters of haemolysis, thrombocytopenia, and renal function tests) evolved after 3-5 days [3]. Completely unexpected, however, was the observation that severe neurological symptoms developed after about 3-10 days in roughly $50 \%$ of patients with HUS, even though clinical and laboratory markers of HUS were improving. These patients who had at first seemed to improve or respond to therapy, deteriorated again. Some patients even had to be re-hospitalised 3-4 days after they had been discharged. Neurologists were very concerned about the severity of neurological symptoms, ranging from mild disorientation and cognitive dissociation to stupor or severe, life-threatening seizures. Despite the impressive clinical presentation, routine neuroradiological examination revealed only mild alterations, if any. Worryingly, especially patients with seizures seemed to respond only weakly to standard antibodybased treatment regimes.

In this issue of Eurosurveillance, Cordesmeyer et al. [4] report about an unusual case of STEC/VTEC 0104: $\mathrm{H}_{4}$ infection associated with colonic ischemia, and Kuijper et al. [5] describe a case of household transmission of STEC 0104: $\mathrm{H}_{4}$ from a mother to her child. In both cases, neurological symptoms were present, with severe manifestation and as yet unclear neurological outcome in the child. From a public health perspective, these and other rather unusual clinical presentations and sequelae of STEC/VTEC 0104: $\mathrm{H}_{4}$ infections are of importance when it comes to supporting and guiding the identification of STEC/VTEC cases, providing recommendations for the follow-up of patients, or adapting existing case definitions for the disease. In order to share and disseminate relevant clinical data among European clinicians and to foster the dialogue between clinicians and epidemiologists, a clinical support initiative was established by the ECDC as a reaction to the outbreak. Nominated clinical contact points, and up to two additional clinical STEC/VTEC experts per EU Member State were invited by the ECDC to join this initiative. It comprises a password-protected internet discussion forum for timely exchange of information, expertise and best practices. In addition, an audio podcast (available through the ECDC website) has been produced, in which a clinical expert from Germany describes his experiences with the presentation, treatment, and outcome of patients infected with STEC/VTEC 0104: $\mathrm{H}_{4}$.

This clinical support initiative is one more component of the European response against this devastating outbreak and the possible future establishment and spread of the new STEC/VTEC 0104:H4 strain in Europe. It will add to and support the ECDCs ongoing efforts in the field of scientific advice, outbreak response and surveillance. 


\section{Acknowledgments}

The clinical support initiative of ECDC is represented by Marc Struelens, Anna-Pelagia Magiorakos, Sybille Rehmet, Susanne Freudenberg, and Andreas Jansen.

\section{References}

1. Scheutz F, Møller Nielsen E, Frimodt-Møller J, Boisen N, Morabito S, et al. Characteristics of the enteroaggregative Shiga toxin/verotoxin-producing Escherichia coli 0104: $\mathrm{H}_{4}$ strain causing the outbreak of haemolytic uraemic syndrome in Germany, May to June 2011. Euro Surveill. 2011;16(24):pii=19889. Available from: http://www. eurosurveillance.org/ViewArticle.aspx?Articleld=19889

2. Bielaszewska M, Mellmann A, Zhang W, Köck R, Fruth A, Bauwens A, et al. The Characterisation of the Escherichia coli strain associated with an outbreak of haemolytic uraemic syndrome in Germany, 2011: a microbiological study. Lancet Infect Dis. Early Online Publication, 23 June 2011. DOI: 10.1016/ S1473-3099(11)70165-7

3. Frank C, Werber D, Cramer JP, Askar M, Faber M, an der Heiden $M$, et al. Epidemic Profile of Shiga-Toxin-Producing Escherichia coli 104: $_{4}$ Outbreak in Germany - Preliminary Report. N Engl J Med. 2011;22 Jun 222011 (10.1056/NEJMoa1106483).

4. Cordesmeyer S, Peitz U, Gödde N, Kasper HU, Hoffmann MW, Allemeyer E. Colonic ischaemia as a severe Shiga toxin/ verotoxin producing Escherichia coli $\mathrm{O}_{104} \mathrm{H}_{4}$ complication in a patient without haemolytic uraemic syndrome, Germany, June 2011. Euro Surveill. 2011;16(25): pii=19895. Available from: http://www.eurosurveillance.org/ViewArticle. aspx?Articleld $=19895$

5. Kuijper EJ, Soonawala D, Vermont C, van Dissel JT. Household transmission of haemolytic uraemic syndrome associated with Escherichia coli 0104: $\mathrm{H}_{4}$ in the Netherlands, May 2011. Euro Surveill. 2011;16(25):pii=19897. Available from: http://www. eurosurveillance.org/ViewArticle.aspx?Articleld=19897 